\title{
Monocular visual outcome in untreated early onset esotropia
}

\author{
William V Good, Luis C F da Sa, Christopher J Lyons, Creig S Hoyt
}

Department of

Ophthalmology,

University of California,

San Francisco, USA

W V Good

L C F da Sa

C J Lyons

CS Hoyt

Correspondence to:

William V Good, MD, 400

Parnassus No 704A, San

Francisco, CA 94143, USA.

Accepted for publication

19 March 1993

\begin{abstract}
The incidence of amblyopia was analysed in a group of 20 patients with early onset esotropia. These patients reached adulthood without any form of previous treatment. The incidence of amblyopia was compared in a group of 20 patients who received conventional treatment, including occlusion and early surgical alignment. Only three patients $(15 \%)$ in the untreated group presented with amblyopia, compared with $16(80 \%)$ in the treated group. After treatment $35 \%$ of the control group remained amblyopic. Spherical anisometropia of more than 2 dioptres was present in two of the patients with amblyopia in the untreated group, but was not associated with amblyopia in the control group. Early surgical alignment permits the development of peripheral fusion, allowing long term alignment stability, but amblyopia appears to be more common after surgical alignment.
\end{abstract}

(BrF Ophthalmol 1993; 77: 492-494)

The current management of infantile esotropia often consists of surgical alignment of the eyes after amblyopia therapy. Studies have shown that alignment by the age of 2 years improves the likelihood of developing fusion. ${ }^{1-3}$ The presence of fusion in turn allows long term stability of alignment. $^{45}$

Table 1 Patients with untreated early onset esotropia and no amblyopia

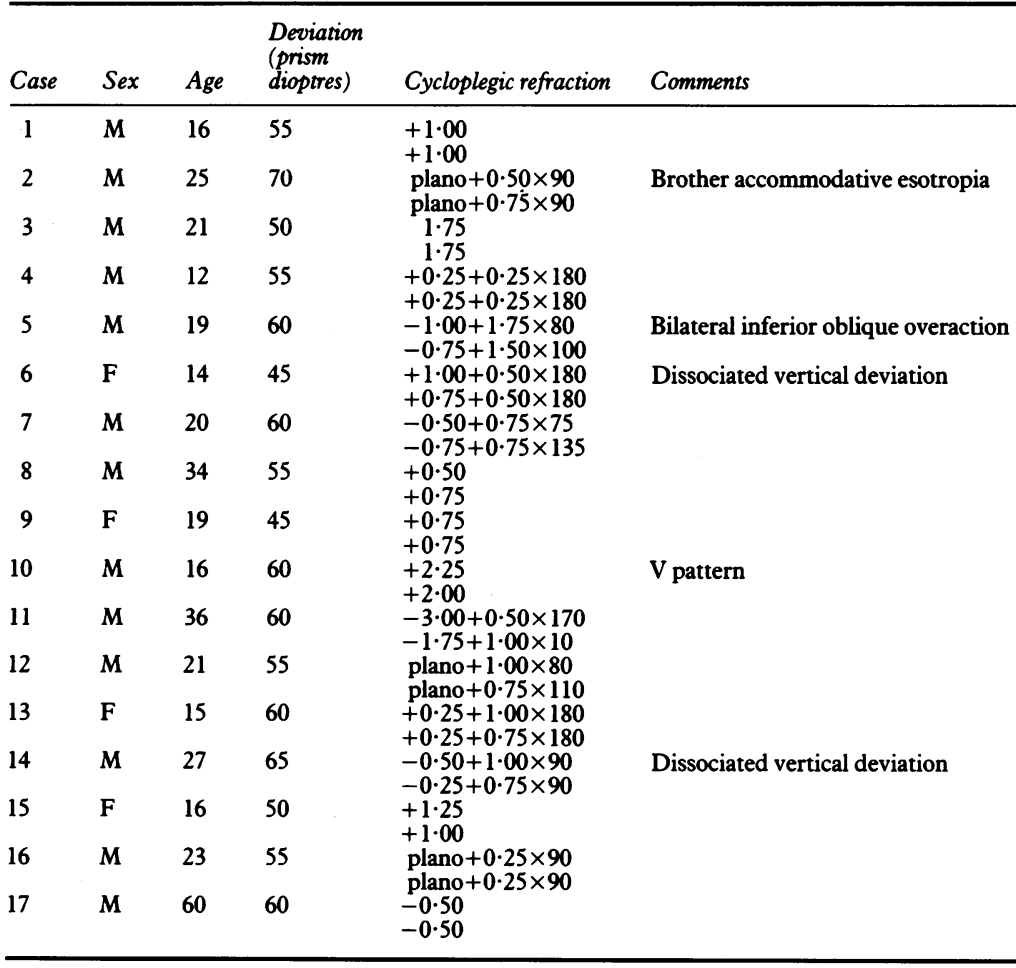

In developing countries where health care standards remain low, infantile strabismus may be left untreated. We examined a group of immigrants from south east Asia who received no medical or orthoptic treatment for early onset strabismus. These patients offer a rare opportunity to study the visual outcome of untreated, early onset esotropia.

\section{Patients and methods}

Between January 1982 and March 199220 patients with a history of early onset strabismus and no previous medical or orthoptic treatment were seen in this department. These patients were all seeking improvement in their cosmetic appearance. All but two had emigrated from Vietnam, Laos, or Cambodia. Their average age was $20 \cdot 3$ years (range 12-34 years). There were 15 males and five females (Tables 1 and 2).

A full ocular examination including cycloplegic refraction was performed by at least one of us (WVG, CSH). The angle of strabismus was measured using the prism cover/uncover technique. Patients were classified as amblyopic if there was a difference of two lines or more in the best corrected visual acuity of each eye.

We reviewed the records of 20 patients with infantile esotropia who were treated conventionally and followed from 11 months to 8 years and 10 months (mean 4 years and 5 months), to verify the incidence of amblyopia in this group of patients. Patients were considered to have amblyopia in the course of treatment if they presented fixation preference, or if there was a difference of two lines or more in the best corrected visual acuity of each eye. These patients were chosen in a consecutive fashion, but only those patients who received surgical care were included.

No other neurological or craniofacial anomaly was identified in any of the patients in this study.

Results

All patients were esotropic, with an angle of deviation ranging from 45 to 70 prism dioptres and a mean of 57 prism dioptres. The angle of

Table 2 Patients with untreated early onset esotropia and amblyopia

\begin{tabular}{|c|c|c|c|c|c|}
\hline Case & Sex & Age & $\begin{array}{l}\text { Deviation } \\
\text { (prism } \\
\text { dioptres) }\end{array}$ & Cycloplegic refraction & $\begin{array}{l}\text { Visual } \\
\text { acuity }\end{array}$ \\
\hline 1 & $\mathbf{M}$ & 24 & 60 & $\begin{array}{l}+0.50+1.00 \times 180 \\
+2.75+1.75 \times 180\end{array}$ & $\begin{array}{l}20 / 20 \\
20 / 200\end{array}$ \\
\hline 2 & $\mathbf{M}$ & 17 & 55 & $\begin{array}{l}+0.50 \\
+0.50\end{array}$ & $\begin{array}{l}20 / 70 \\
20 / 20\end{array}$ \\
\hline 3 & $\mathbf{F}$ & 26 & 65 & $\begin{array}{l}-0.50+0.75 \times 90 \\
-2.50+0.50 \times 85\end{array}$ & $\begin{array}{l}20 / 20 \\
20 / 100\end{array}$ \\
\hline
\end{tabular}


Table 3 Patients submitted to conventional treatment

\begin{tabular}{lcc}
\hline & Amblyopia & No amblyopia \\
\hline Preoperatively (\%) & $4(20)$ & $16(80)$ \\
Postoperatively (\%) & $16(80)$ & $4(20)$ \\
Final (\%) & $7(35)$ & $13(65)$ \\
\hline
\end{tabular}

strabismus and refraction of each patient is shown in Tables 1 and 2.

Amblyopia was detected in three of the 20 patients $(15 \%)$ (Table 2$)$. These three patients had a corrected visual acuity of $20 / 20$ in the preferred eye, while the vision in the amblyopic eye ranged from 20/70 to 20/100. Dissociated vertical deviation was detected in two patients and inferior oblique overaction in one. Thirteen patients had latent nystagmus.

Two amblyopic patients (cases 1 and 2) had more than 2 dioptres of spherical anisometropia. The third amblyopic patient (case 3) had the same refractive error in each eye.

In the 17 patients with no amblyopia, the difference in the spherical portion was 0.25 dioptres in seven patients and 1.75 dioptres in one patient. There were no patients with a difference greater than 0.25 dioptres of astigmatism in each eye, and no asymmetry in the angle of the cylinder.

In the group of 20 patients submitted to conventional treatment, four $(20 \%)$ patients had amblyopia before surgery (Table 3). After surgery 16 patients $(80 \%)$ required occlusion because of amblyopia during follow up. Only seven $(35 \%)$ patients remained amblyopic at the last visit (Table 3). There was no spherical or cylindrical anisometropia greater than 0.5 dioptres in this group.

\section{Discussion}

Treatment of early onset esotropia is designed to achieve good visual acuity in both eyes, to obtain a degree of binocular vision, and to align the eyes. Occlusion is used to treat amblyopia. Surgical alignment is undertaken when amblyopia has been successfully treated. The results of this method of management of infantile esotropia show that ocular alignment can be achieved in $50-80 \%$ of cases. ${ }^{126}$ Some form of binocularity is present in $48-70 \% .^{1-37}$ Surgical correction may even result in improvement of fine motor skills and motor maturation. ${ }^{8}$

Despite the satisfying results and indications for early surgery, the surgeon risks inducing amblyopia in patients who are successfully surgically aligned. Costenbader found that $41 \%$ of patients treated for congenital esotropia were amblyopic. ${ }^{6}$ Others have reported an incidence of amblyopia after treatment ranging from 20 to $51 \% .^{910}$ When postoperative amblyopia was studied using vision evoked potential measurements, the incidence was $61 \%$ (v $20 \%$ preoperatively)."

We had the opportunity to examine 20 adult patients with untreated early onset esotropia who had immigrated to the United States from Asia. These patients offered us the unusual opportunity to evaluate the natural history of early onset esotropia, and to assess visual outcome. We compared this adult immigrant population with a group of children who received early surgical therapy. Amblyopia was present in three (15\%) untreated, adult patients. This finding supports the study by Murray and Calcutt in which amblyopia was uncommon in untreated early onset esotropia. ${ }^{12}$ Two of our patients had anisometropia of 2.0 and 2.25 dioptres respectively. In the control group amblyopia occurred in $20 \%$ before surgery, but in $80 \%$ after surgical treatment; $35 \%$ of the control group remained amblyopic after treatment. Two patients in the study group had dissociated vertical deviation (DVD) and one had inferior oblique overaction.

Inclusion in the study group of patients was based on history and physical findings. The patients would probably have been diagnosed with early infantile esotropia. It is unlikely that these patients had a heterogeneous mix of different types of esotropia. The angle of deviation in the study group was large, with no significant abnormality of the AC/A ratio or accommodative component to the esotropia. The refractive errors in the study group of patients were, for the most part, low. Most children with accommodative esotropia will remain hyperopic in adulthood. ${ }^{13}$ Furthermore, 13 patients had latent nystagmus, a finding consistent with a diagnosis of early infantile esotropia.

The incidence of vertical strabismus abnormalities in our patients was low; DVD occurred in $10 \%$, whereas in other reports looking at young patients, the incidence has been as high as $76 \% .^{7}$ DVD is a variable problem and its evaluation is often highly subjective. The low incidence in our report could indicate that our patients are different from others with early onset esotropia. More likely, the natural history of DVD is one in which improvement occurs. Parks ${ }^{14}$ has commented on this possibility and noted that DVD frequently disappears by the age of 8 . Harcourt et $a l^{15}$ found no change in the incidence of DVD in children followed for an average of $7 \cdot 3$ years. However, this study found a very low incidence (2\%) of DVD requiring surgery and did not follow patients to adulthood. It may be that DVD is expressed after surgical alignment and is uncommon in untreated infantile esotropes.

Inferior oblique overaction (IOOA) was also uncommon (5\%) in our study group of patients. This compared with an incidence of nearly $75 \%$ reported in other studies in which children were examined. ${ }^{76}$ Wilson and Parks ${ }^{16}$ noted that children who underwent surgery for horizontal alignment were more likely to develop IOOA. Some of our patients could have been spared IOOA by not having had prior surgery. Our study also suggests a possible decline with age in the incidence of IOOA associated with early onset, untreated esotropia.

Why was the incidence of amblyopia low in our study group compared with the control group ( $80 \%$ after surgery) (Table 2)? One risk factor for amblyopia could be asymmetric IOOA,${ }^{17}$ a finding not present in our adult group. Asymmetric IOOA could lead to amblyopia, purely on the basis of motor factors. A hypertropic eye is at risk for amblyopia.

Amblyopia was often diagnosed by the fixation reflex in the control group of children. This test may overestimate the incidence of amblyopia 
when the angle of strabismus is large, particularly if the point at which cross fixation occurs is not carefully observed. ${ }^{18}$ We only diagnosed amblyopia by cross fixation testing when cross fixation occurred beyond the midline.

Fixation reflex testing may also overestimate the incidence of amblyopia in patients with small angles of deviation. Some members of our control group were diagnosed with amblyopia via fixation reflex. Unfortunately, there is no entirely reliable method for ascertaining amblyopia in preverbal children, particularly with small angles of deviation. Visually evoked potential studies tend to be too sensitive, ${ }^{11}$ and forced preferential looking techniques may underestimate the incidence of amblyopia. ${ }^{19} 20$

When amblyopia was determined by Snellen acuity measurements in the untreated adult group, the incidence was low. This group showed cross fixation patterns characteristic of preverbal, presumably non-amblyopic children - that is, they cross fixated at the midline. This finding suggests that midline cross fixation ( $v$ off centre) is an accurate method for detecting amblyopia.

Our study shows that large angle esotropia usually protects the patient from amblyopia. Some studies have indicated a high incidence of amblyopia in young children who cross fixate. ${ }^{71}$ Our study indicates that left untreated, many develop normal, equal vision ${ }^{18}$ in their two eyes. Our explanation for this is as follows. Both maculae will experience visual stimulation in cross fixation, albeit one may be stimulated more than the other if cross fixation occurs beyond the midline. At first this situation may cause amblyopia. But note that even when vision is equal in both eyes, it is usually below average (early on) in children with early infantile esotropia. ${ }^{21}$ Part time visual stimulation of the amblyopic eye is analogous to part time occlusion. As time passes, the cross fixating child develops equal, bilateral vision and is more content to cross fixate at the midline position.

Macular stimulation may be pre-empted in children with small angles of esotropia. Peripheral fusion functions as a lock and may prevent one eye from obtaining adequate central macular visual stimulation. In this setting children may not cross fixate because they do not need to. Their eyes are centred and move left and right with full range of motion.

Cross fixation occurs as a result of sensory influences, but it can be overriden in two circumstances. The first circumstance occurs in the child with uneven visual input. Two of our adult patients with amblyopia had anisometropia. Anisometropia may be associated with unreversed preoperative amblyopia in congenital esotropia. ${ }^{22}$ Secondly, motor factors could force a child with early infantile esotropia to prefer to use one eye. Amblyopia is common in children with congenital esotropia and nystagmus, ${ }^{23}$ a situation in which abducting nystagmus may influence a child to prefer one eye.

We have already noted the many advantages to surgical aligment for early infantile esotropia. Despite the high incidence of postoperative amblyopia in our control group, the final incidence of amblyopia after treatment could be reduced to $35 \%$. We do not recommend withholding treatment, but it is interesting to note that many of the features of early onset esotropia appear to be self correcting. Amblyopia, in particular, was uncommon in our group of untreated patients.

Christopher J Lyons was supported by a grant from the Frost Charitable Trust, London.

1 Ing M, Costenbader FD, Parks MM, Albert DG. Early surgery for congenital esotropia. Am f Ophthalmol 1966; 61 1419-27.

2 Foster RS, Paul OT, Jampolsky A. Management of infantile esotropia. Am f Ophthalmol 1976; 82: 291-9.

3 von Noorden GK. A reassessment of infantile esotropia. (XLIV Edward Jackson Memorial Lecture.) $\mathrm{Am} f$ Ophthalmol 1988; 105: 1-10.

4 Jampolsky A. A simplified approach to strabismus diagnosis. In: Strabismus symposium. Trans New Orleans Acad In: Strabismus symposium. Trans Nen

5 Fisher NF. The relationship between stereoacuity and stable binocular vision. $\mathcal{F}$ Pediatr Ophthalmol Strabismus 1973; 10 275-7.

6 Costenbader FD. Infantile esotropia. Trans Am Ophthalmo Soc 1961; 59: 397-429.

7 Hiles DA, Watson A, Biglan AW. Characteristics of infantile esotropia following bimedial recession. Arch Ophthalmol 1980; 98: 697-703.

8 Rogers GL, Chazan S, Fellows R. Strabismus surgery and its effects upon infant development in congenital esotropia. Ophthalmology 1982; 89: 479-83.

9 Parks MM. Operate early for congenital strabismus. In: Brockhurts RJ, Boruchoff SA, Hutchinson BT, et al, eds Controversy in ophthalmology. Philadelphia: Saunders, 1977 493.

10 Pratt-Johnson JA, Tillson G. Sensory results following treat ment of infantile esotropia. Can $\mathcal{F}$ Ophthalmol 1983; 18: 175-7.

11 Hoyt CS, Jastrzebski GB, Marg E. Amblyopia and congenital esotropia. Visually evoked potential measurements. Arch Ophthalmol 1984; 102: 58-61.

12 Murray ADN, Calcutt $C$. The incidence of amblyopia in long standing untreated infantile esotropia. In: Campos EC, ed. Strabismus and ocular motility disorders. London: MacMillan, Strabismus and

13 Swan KC. Accommodative esotropia. Long range follow up. Ophthalmology 1983; 90: 1141-5.

14 Parks MM. Ocular motility and strabismus. Hagertown, MD Harper and Row, 151

15 Harcourt B, Mein J, Johnson F. Natural history and association of dissociated vertical divergence. Trans Ophthalmol So UK 1980; 100: 495-7.

16 Wilson ME, Parks MM. Primary inferior oblique overaction in congenital esotropia, accommodative exotropia, and intermittent esotropia. Ophthalmology 1989; 96: 950-2.

17 Weakley DR, Urso RG, Dias CL. Asymmetric inferior oblique overaction and its association with amblyopia and esotropia. Operaction and its association with

18 Dickey CF, Metz HS, Stewart SA, Scott WE. The diagnosis of amblyopia in cross-fixation. F Pediatr Ophthalmol Strabismus 1991; 28: 171-5.

19 Mayer DL, Fulton AB. Preferential looking grading acuities of infants at risk of amblyopia. Trans Ophthalmol Soc UK 1985 104: 903.

20 Birth EE, Stager DR. Monocular acuity and stereopsis in infantile esotropia. Invest Ophthalmol Vis Sci 1985; 26: 1624

21 Dobson V, Sebris SL. Longitudinal study of acuity and stereopsis in infants with or at risk for esotropia. Invest Stereopsis in infants with or at risk
Ophthalmol Vis Sci 1989; 30: $1146-58$.

22 Kennan JN, Willshaw HE. Outcome of strabismus surgery in congenital esotropia. Brf Ophthalmol 1992; 76: 342-5.

23 von Noorden GK. The nystagmus compensation (blockage) syndrome. Am $\mathcal{F}$ Ophthalmol 1976; 82: 283-90. 